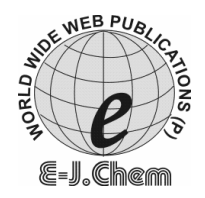

\title{
Inhibition of Aluminium Corrosion in Hydrochloric Acid Using Nizoral and the Effect of Iodide Ion Addition
}

\author{
I.B. OBOT* and N.O. OBI-EGBEDI \\ *Department of Chemistry, \\ Faculty of Science, University of Uyo, Uyo, Nigeria. \\ Department of Chemistry, University of Ibadan, Ibadan, Nigeria. \\ proffoime@yahoo.com
}

Received 21 July 2009; Revised 3 September 2009; Accepted 1 November 2009

\begin{abstract}
The effect of nizoral (NZR) on the corrosion inhibition of aluminium alloy AA 1060 in $2 \mathrm{M} \mathrm{HCl}$ solution was investigated using the mylius thermometric technique. Results of the study revealed that nizoral acts as corrosion inhibitor for aluminium in the acidic medium. In general, at constant acid concentration, the inhibition efficiency increases with increase in the inhibitor concentration. The addition of KI to the inhibitor enhanced the inhibition efficiency to a considerable extent. The adsorption of nizoral onto the aluminium surface was found to obey the Fruendlich adsorption isotherm. The value of the free energy for the adsorption process shows that the process is spontaneous.
\end{abstract}

Keywords: Nizoral, Aluminium, Corrosion inhibition, Adsorption isotherm, Hydrochloric acid.

\section{Introduction}

Aluminium is a metal with a high electronegative potential $(-1.67 \mathrm{~V})$. It is also highly resistant to most acidic and neutral solutions due to the formation of a protective oxide film on its surface. This film is responsible for the corrosion resistant of aluminium in most environments ${ }^{1}$. Nevertheless, in some cases, aluminium may be exposed to high concentrations of acids or bases. These solutions dissolve the passive film. Under these circumstances, corrosion inhibitors should be used.

The use of chemical inhibitors for aluminium alloy has been established to be the most practical and cost effective means of preventing corrosion ${ }^{2-5}$. Most of the well known acid inhibitors are organic compounds containing nitrogen, sulphur and/or oxygen atoms. Moreover, many $N$-heterocyclic compounds have been proved to be effective inhibitors for the corrosion of metals and alloys in aqueous media ${ }^{6-9}$. The influence of organic compounds containing nitrogen on the corrosion of aluminium in acidic solutions has been investigated 
by several authors ${ }^{10-14}$. These organic compounds can adsorb on the metal surface, block the active sites on the surface and thereby reduce the corrosion rate.

Recently, the use of drugs as corrosion inhibitors for metals in various aggressive media has generated a lot of interest. Although not much work have been done in this area of study, it will serve as a possible replacement for toxic, costly and ecologically unfriendly organic inhibitors now in use. Some of the few reports on the use of drugs as corrosion inhibitors to date include the work of Abdallah ${ }^{15,16}$ on rhodanine azosulpha drugs and antimalarial drugs and El-Naggar ${ }^{17}$ on sulpha drugs.

Therefore the aim of the present investigation is to study the corrosion inhibition of aluminium in acid environments $(\mathrm{HCl})$ by nizoral, an antifungal drug, using thermometric method. The effect of iodide addition on the inhibition efficiency of the inhibitor is also studied. As a drug, nizoral was found to be a heterocyclic compound containing $\mathrm{O}, \mathrm{N}$ atoms and $\pi$ bonds that were regarded as important factors for a good inhibitor. Besides, nizoral is very cheap, easily available, and the most important, nontoxic. Furthermore, the molecule is big enough (molecular weight 508.4) and likely to effectively cover more surface area (due to adsorption) of the $\mathrm{Al}$ metal.

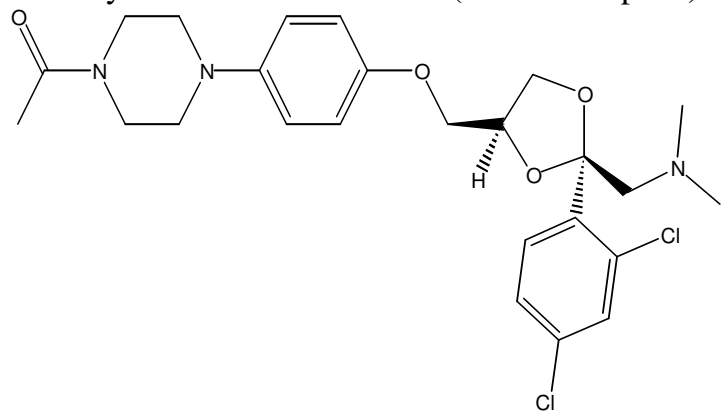

1-[4-[4-[[(2S,4R)-2-(2,4-dichlorophenyl)-2-(imidazol-1-ylmethyl)-1,3-dioxolan-4yl]methoxy]phenyl]piperazin-1-yl]ethanone

\section{Experimental}

Figure 1. The chemical structure of nizoral.

The sheets of aluminium, AA 1060 type and purity 98.5 per cent used for this study were obtained from Ibom Metals Ltd, Uyo, Nigeria. Each sheet was $0.8 \mathrm{~mm}$ in thickness and were mechanically pressed cut into $5 \times 4 \mathrm{~cm}$ coupons. These coupons were used as cut without further polishing. However, they were degreased in ethanol, dried in acetone and stored in a moisture free desiccator before their use in corrosion studies. Nizoral was obtained commercially from a pharmaceutical shop in Uyo, Nigeria. The concentrations of the inhibitor (NZR) prepared and used in the study were $2 \times 10^{-5}-10 \times 10^{-5} \mathrm{M}$. The concentrations of $\mathrm{HCl}$ (blank) (BDH chemicals, England) used were in the range 1.0 - 3.0 M. The KI was also from BDH chemicals, England and the concentrations prepared were 0.001- $0.005 \mathrm{M}$. However, 0.005 M KI solution was used for the synergistic studies.

\section{Thermometric method}

This is one of the sensitive methods used in corrosion monitoring. This method has proved to be of considerable value and help in studying corrosion behavior of a number of metals and alloys in various corroding environments ${ }^{18-21}$. Results obtained by the thermometric method were confirmed by well-established methods such as weight loss ${ }^{22}$ and hydrogen evolution measurements ${ }^{23}$. The reaction vessel and procedure for determining the corrosion behavior by this method was first reported by Mylius ${ }^{24}$ and described elsewhere ${ }^{25-27}$. In this 
method, the aluminium coupons were completely immersed in $2 \mathrm{M} \mathrm{HCl}$ solution (blank), and in combination with different concentrations of the iodide, inhibitor and inhibitoriodide mixture. The volume of the test solution was kept at $50 \mathrm{~mL}$. The initial temperature in all experiments was kept at $30{ }^{\circ} \mathrm{C}$. The temperature was measured to $\pm 0.05{ }^{\circ} \mathrm{C}$ on a calibrated thermometer $\left(0-100{ }^{\circ} \mathrm{C}\right)$. This method allowed for the evaluation of the reaction number $(\mathrm{RN})$. The $\mathrm{RN}$ is defined as

$$
R N\left({ }^{\circ} C \min ^{-1}\right)=\frac{T_{m}-T_{i}}{t}
$$

Where $T_{m}$ and $T_{i}$ are the maximum and initial temperatures respectively and ' $t$ ' is the time (min) taken to reach the maximum temperature. The inhibition efficiency (\%I) was evaluated from percentage reduction in the reaction number using equation (2).

$$
\% I=\frac{R N_{a q}-R N_{w i}}{R N_{a q}} \times 100
$$

Where $R N_{a q}$ is the reaction number in the absence of inhibitor (blank solution) and $R N_{w i}$ is the reaction number of $2 \mathrm{M} \mathrm{HCl}$ containing studied inhibitor.

\section{Results and Discussion}

\section{Thermometric measurements}

The effect of corrodent $(\mathrm{HCl})$ concentration on the corrosion of aluminium is illustrated in the plot of temperature $\left({ }^{\circ} \mathrm{C}\right)$ against time (min) at different concentrations of $\mathrm{HCl}$ as shown in Figure 2. From the plot, it is observed that the dissolution of aluminium starts after a certain time from the immersion of the aluminium coupon in the test solution. It may be expected that this time corresponded to the period/time needed by the acid to destroy the pre-immersion oxide film and is known as incubation period. After this point, the temperature rises gradually with time and then decreases after reaching a maximum temperature, $T_{m}$. Also from Figure 2, it is observed that as the concentration of the corrodent increases, the maximum temperature, $T_{m}$ increases and the time required to reach the maximum temperature decreases. These observations are attributed to the fact that increase in $\mathrm{HCl}$ concentration gives rise to a corresponding increase in the concentrations of active species as well as increase in the rate of chemical reaction.

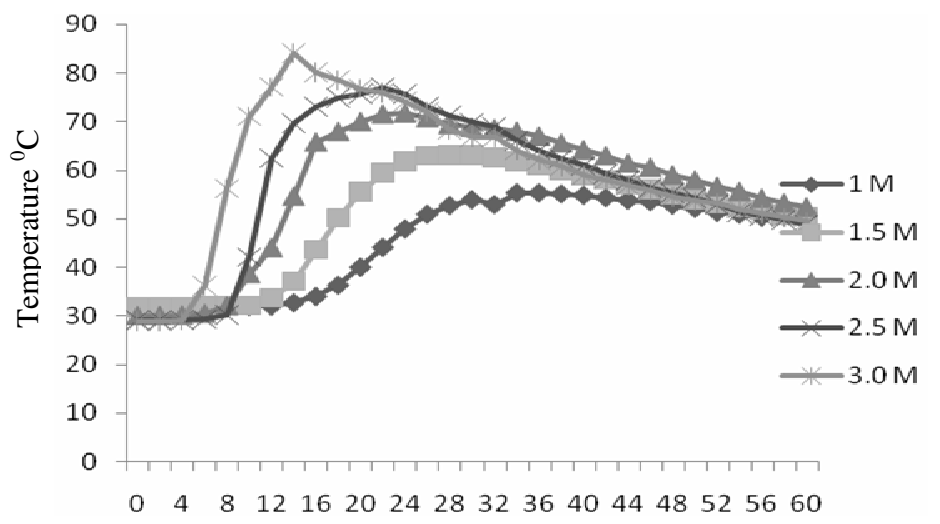

Time, mins

Figure 2. Variation of temperature with time for the dissolution of aluminium in different concentrations of $\mathrm{HCl}$ (Blank). 
Temperature change of the system involving aluminium in $2 \mathrm{M} \mathrm{HCl}$ was followed as a function of time in the absence and presence of different concentrations of NZR (Figure 3). The maximum temperature $\left(T_{m}\right)$ measured in the free acid solution is $72.0{ }^{\circ} \mathrm{C}$ and was attained after time $(t)$ of $23 \mathrm{~min}$. This corresponds to a reaction number (RN) of $1.83{ }^{\circ} \mathrm{C} / \mathrm{min}$. Addition of Nizoral caused a decreased in the maximum temperature and an increase in the time required to reach it. This indicates that nizoral (NZR) retards the dissolution rate of aluminium in the acidic solution, presumably by its adsorption on the metal surface. The extent of inhibition depends on the degree of coverage of the metal by the adsorbed molecules. Similar observations has been reported elsewhere ${ }^{28}$. Adsorption is noted for nizoral, since a simultaneous increase in $t$ and decrease in $T_{m}$ takes place, and both the factors cause a large decrease in the reaction number $\mathrm{RN}$ of the system (Table 1 ). Increasing the nizoral concentration in the acid solution decreases the $\mathrm{RN}$ of aluminium and consequently the inhibition efficiency $\% \mathrm{I}$ is increased.

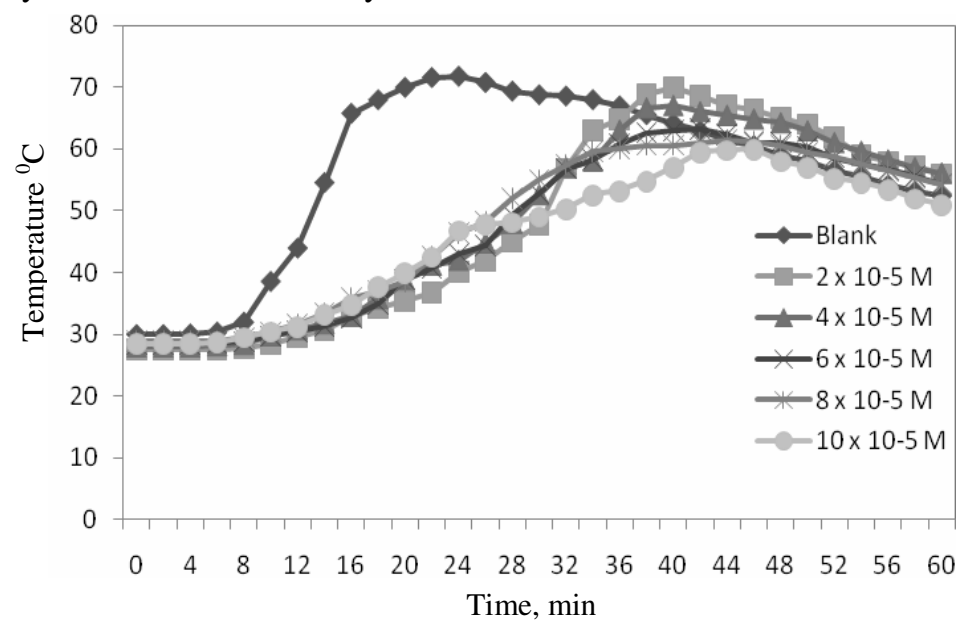

Figure 3. Variation of temperature with time for the dissolution of aluminium in the absence and in different concentrations of nizoral.

Table 1. Calculated values of Reaction Number (RN) and Inhibition efficiency (\% I) in the absence and presence of different concentrations of nizoral

\begin{tabular}{ccc}
\hline System/Concentration, M & Reaction number, RN & Inhibition efficiency, \% I \\
\hline Blank & 1.826 & - \\
$2 \times 10^{-5}$ & 1.000 & 45.36 \\
$4 \times 10^{-5}$ & 0.881 & 51.86 \\
$6 \times 10^{-5}$ & 0.755 & 58.77 \\
$8 \times 10^{-5}$ & 0.683 & 62.69 \\
$10 \times 10^{-5}$ & 0.625 & 65.85 \\
\hline
\end{tabular}

Figure 4 shows the temperature - time curves for the dissolution of aluminium in different concentrations of nizoral + iodide mixture. A closer look at Figure 4 shows a further reduction in the maximum temperature $T_{m}$, and a further increase in the time required to reach it. This shows that nizoral in combination with iodide ions further retards the dissolution rate of aluminium in acidic medium when compared to NZR alone. The inhibition efficiency increased up to $69.40 \%$ at a concentration of $0.005 \mathrm{M} \mathrm{KI}+10 \times 10^{-5} \mathrm{M}$ of the mixture (Table 2). 


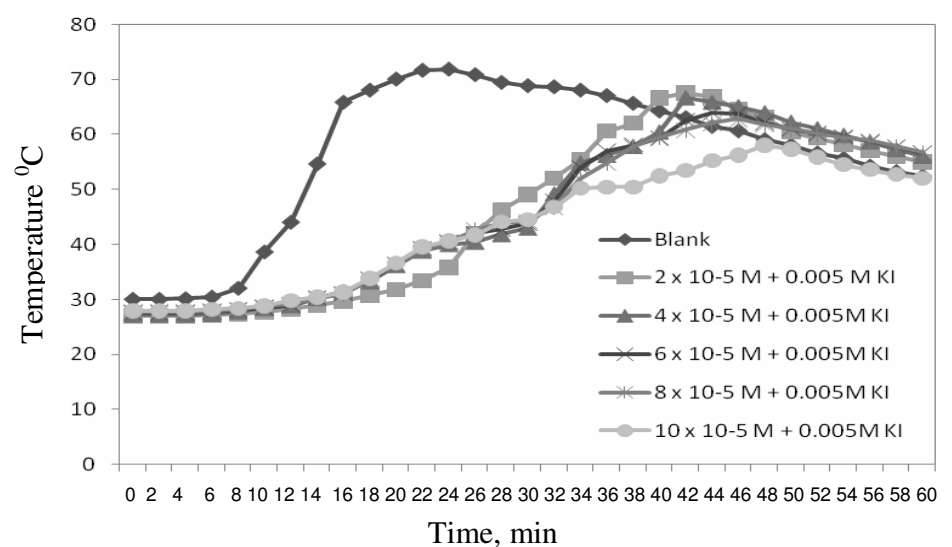

Figure 4. Variation of temperature with time for the dissolution of aluminium in the absence and in different concentrations of nizoral $+\mathrm{KI}$ mixture.

Table 2. Calculated values of Reaction Number (RN) and Inhibition efficiency (\% I) in the absence and presence of different concentrations of nizoral+ iodide mixture.

\begin{tabular}{ccc}
\hline System/Concentration & Reaction number, RN & Inhibition efficiency, \% I \\
\hline Blank & 1.826 & - \\
$0.005 \mathrm{M} \mathrm{KI}+2 \times 10^{-5} \mathrm{M}$ & 0.927 & 49.35 \\
$0.005 \mathrm{M} \mathrm{KI}+4 \times 10^{-5} \mathrm{M}$ & 0.851 & 53.49 \\
$0.005 \mathrm{M} \mathrm{KI}+6 \times 10^{-5} \mathrm{M}$ & 0.756 & 60.00 \\
$0.005 \mathrm{M} \mathrm{KI}+8 \times 10^{-5} \mathrm{M}$ & 0.694 & 65.00 \\
$0.005 \mathrm{M} \mathrm{KI}+10 \times 10^{-5} \mathrm{M}$ & 0.560 & 69.40 \\
\hline
\end{tabular}

The Inhibition of NZR can be explained in terms of adsorption on the metal surface. The compound can be adsorbed by the interaction between the lone pairs of electrons on the nitrogen and oxygen atoms and the metal surface. This process is facilitated by the presence of vacant low energy $d$-orbitals in the aluminium atom. Moreover, the formation of positively charged protonated NZR species in acidic solutions facilitates adsorption of the compound on the metal surface through electrostatic interaction between the organic molecules and the metal surface ${ }^{29}$.

Table 2 gives the calculated values of reaction number (RN) and Inhibition efficiency (\% I) for various concentrations of nizoral + iodide mixture. It is evident from the Table that the addition of KI improves the inhibition efficiency of NZR significantly. The synergistic effect between NZR and KI is due to the interactions between chemisorbed $\mathrm{I}^{-}$and organic cation $\mathrm{NZR}^{+}$. The stabilization of adsorbed $\mathrm{NZR}^{+}$on the surface, which may be exhibited by electrostatic interactions with $\mathrm{I}^{-}$ions, leads to higher surface coverage and hence greater corrosion inhibition. Similar observations have been reported elsewhere ${ }^{30}$.

\section{Adsorption considerations}

It has been reported that the adsorption of an organic inhibitor is dependent on the following physicochemical properties of the inhibitor molecule, such as steric factors, functional groups, electron density (i.e. charge distribution) at the atoms and $\pi$ orbital character of donating electrons and on the natures of substrate metals and the type of interaction between organic molecules and the metallic surface as well ${ }^{31}$. In other words, the efficiency of an organic compound as corrosion inhibitor depends not only on the characteristics of the environment in which it acts, the nature of the metal surface and electrochemical potential at the 
interface, but also on the structure of the inhibitor itself, which includes the number of adsorption active centres in the molecule, their charge density, the molecule size, the mode of adsorption, the formation of metallic complexes and the projected area of the inhibitor on the metallic surface ${ }^{32}$.

Basic information on the interaction between the inhibitor and the alloy surface can be provided by the adsorption isotherm. Thus, many adsorption isotherms were plotted to describe this interaction and the Freundlich adsorption isotherm was found to be the best description of the adsorption behavior of the studied inhibitor on the aluminium surface. According to this isotherm, the inhibition efficiency (\% I) is related to the equilibrium adsorption constant $\mathrm{K}$ and the inhibitor concentration $\mathrm{C}$ by the following equation:

$$
\% I=K C^{n}
$$

Where $0<\mathrm{n}<1$, or

$$
\log \% I=\ln K+n \log C
$$

The plots of logarithm of $\%$ I versus logarithm of the concentrations of the inhibitor were made for the inhibitor and the inhibitor + iodide mixtue at $30{ }^{\circ} \mathrm{C}$ (Figure $5 \& 6$ ). Linear plots were obtained in both cases with the correlation coefficient $\left(\mathrm{R}^{2}\right)$ greater than 0.95 , which suggest that the experimental data fit the Freundlich adsorption isotherm.

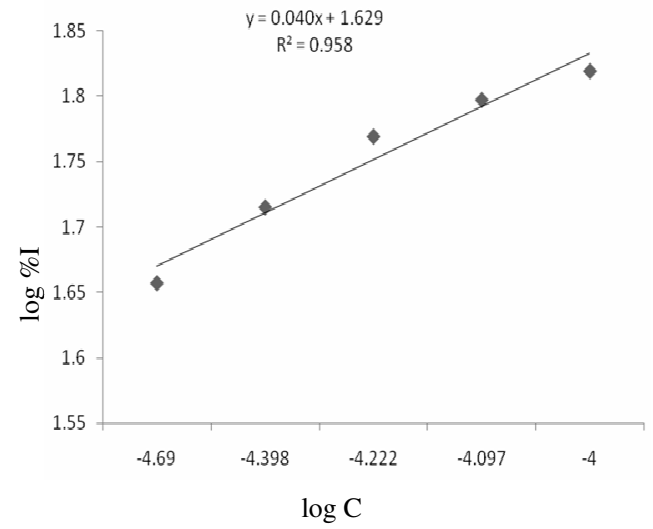

Figure 5. A plot of logarithm inhibition efficiency against logarithm of concentration for nizoral.

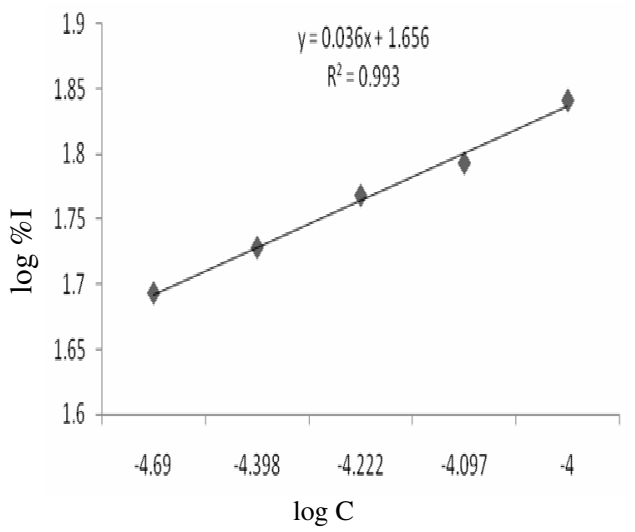

Figure 6. A plot of logarithm inhibition efficiency against logarithm of concentration for nizoral + KI mixture.

$\mathrm{K}$ the equilibrium constant for adsorption which is evaluated from the intercept of the plots and is related to the standard free energy of adsorption, $\Delta \mathrm{G}_{\mathrm{ads}}$ by

$$
K=\frac{1}{55.5} \exp \left[\frac{-\Delta G_{a d s}^{o}}{R T}\right]
$$

The calculated values of $\mathrm{K}$ and $\Delta \mathrm{G}_{\mathrm{ads}}$ are 42.55 and $-13.77 \mathrm{~kJ} / \mathrm{mol}$ for nizoral and 45.28 and $-19.72 \mathrm{~kJ} / \mathrm{mol}$ for nizoral + iodide mixture respectively. It is clear that the values of $\mathrm{K}$ are low indicating weak interaction between the inhibitor and the aluminum surface ${ }^{4}$. The negative values of $\Delta G_{a d s}^{o}$ ensure the spontaneity of the adsorption process and stability of the adsorbed layer on the aluminium surface. Generally, values of $\Delta G_{\text {ads }}^{o}$ up to $-20 \mathrm{kJmol}^{-1}$ are consistent with electrostatic interactions between the charged molecules and the charged metal (physisorption) while those around $-40 \mathrm{kJmol}^{-1}$ or higher are associated with chemisorption as a result of sharing or transfer of electrons from organic molecules to the metal surface to form a coordinate type of bond (chemisorption) ${ }^{5}$. One can see that the calculated $\Delta G_{a d s}^{o}$ values, are less than $-20 \mathrm{kJmol}^{-1}$, indicating, 
therefore, that the adsorption mechanism of $\mathrm{NZR}$ on $\mathrm{Al}$ in $2 \mathrm{M} \mathrm{HCl}$ solution was typical of physisorption.

\section{Conclusions}

1. Nizoral was found to be an inhibitor for aluminium corrosion in acidic medium.

2. Inhibition efficiency increases with increasing inhibitor concentration.

3. The experimental data obtained in this study fits into Freundlich adsorption isotherm.

4. The addition of iodide ions to nizoral enhances the inhibition efficiency to a considerable extent.

5. The negative value of the free energy of adsorption is an indication of the spontaneity of the adsorption process.

\section{References}

1. Umoren S A, Obot I B, Akpabio LE and Etuk S E, Pigment Resin Tech., 2008, 37(2), 98.

2. Umoren S A, Obot I B, Ebenso E E, Okafor P C, Ogbobe O and Oguzie E E, AntiCorros Mater Methods, 2006, 53 (5), 277.

3. Umoren S A and Obot I B, E Journal of Chemistry, 2008, 5(2), 355.

4. Umoren S A, Obot I B, Ebenso E E and Okafor P C, Portugaliae Electrochimica Acta, 2008, 26, 267.

5. Umoren S A, Obot I B, Ebenso E E and Obi-Egbedi N O, Portugaliae Electrochimica Acta, 2008, 26, 199.

6. Umoren S A and Obot I B, Surface Review Lett., 2008, 15(3), 277.

7. Ergun U, Yuzer D and Emregul C, Mater Chem Phys., 2008, 109, 492.

8. Ozcan M, Karadag F and Dehri I. Colloids Surf A: Physicochem Eng Aspects., 2008, 316, 55.

9. Saliyan V R and Adhikari A V, Corros Sci., 2008, 50, 55.

10. Fiala A, Chibani A, Boulkamh A and Djebbar K, Appl Surf Sci., 2007, 253, 9347.

11. Hasanov R, Sadikoglu M and Bilgic S, Appl Surf Sci., 2007, 253, 3913.

12. Al-Juaid S S, Portugaliae Electrochimica Acta., 2007, 25, 363.

13. Allam N K, Appl Surf Sci., 2007, 253, 4570.

14. Ali S A,Muallem H A, Saeed M T and Rahman S U, Corros Sci., 2008, 50, 664.

15. Abdallah M, Corros Sci., 2002, 44, 728.

16. Abdallah M, Corros Sci., 2004, 461996.

17 El-Naggar M M, Corros Sci., 2007, 49, 2226.

18. Moussa M N, Fouda A S, Taha F I and Eluenna A, Bull Korean Chem Soc., 1988, 9(4) 191.

19. Ebenso E E, Nigerian Corros J., 1998, 1, 9.

20. ABD Kader, J M and Shams Eldin, A M, Corros Sci., 1970, 10, 551.

21. Shams Eldin A M and Khedr M G A, Metalloberft, 1972, 25, 200.

22. El -Etre A Y, Corros Sci., 2001, 43, 1031.

23. Umoren S A and Ebenso E E, Pigment Resin Technol., 2008, 37(3), 173.

24. Mylius F, Z. Metallk, 1922, 14, 239.

25. Eddy N O and Ebenso E E, Afri, J Pure Appl Chem., 2008, 2(6), 46.

26. Umoren S A, Cellulose, DOI 10.1007/s10570-008-9226-4.

27. Aziz A and Shams Elden A M, Corros Sci., 1965, 5, 489.

28. Noor E A, Corros Sci., 2005, 47, 33.

29. Larabi L, Harek Y, Traisnel M and Mansri A, J Appl Electrochem., 2004, 34, 833.

30. Umoren S A and Ebenso E E, Mater Chem Phys., 2007, 106, 393.

31. Bouklah M, Benchat N, Hammouti B, Aouniti A and Kertit S, Mater Lett., 2006, 60, 1901.

32. Vracar L M and Drazic D M, Corros Sci., 2002, 44, 1669. 


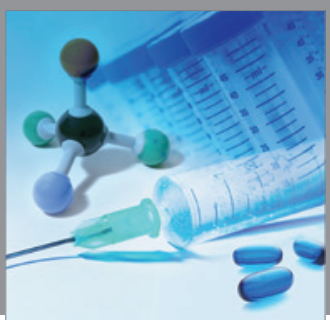

International Journal of

Medicinal Chemistry

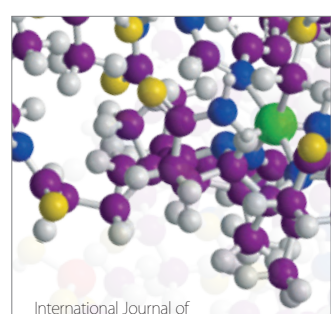

Carbohydrate Chemistry

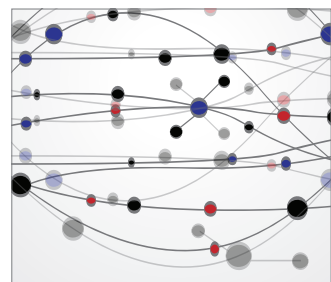

The Scientific World Journal
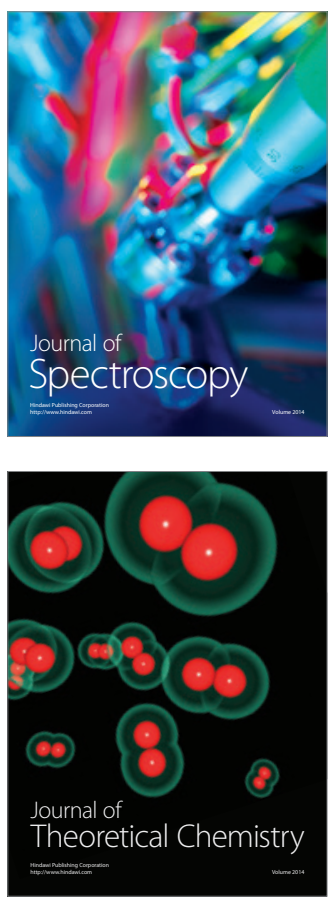
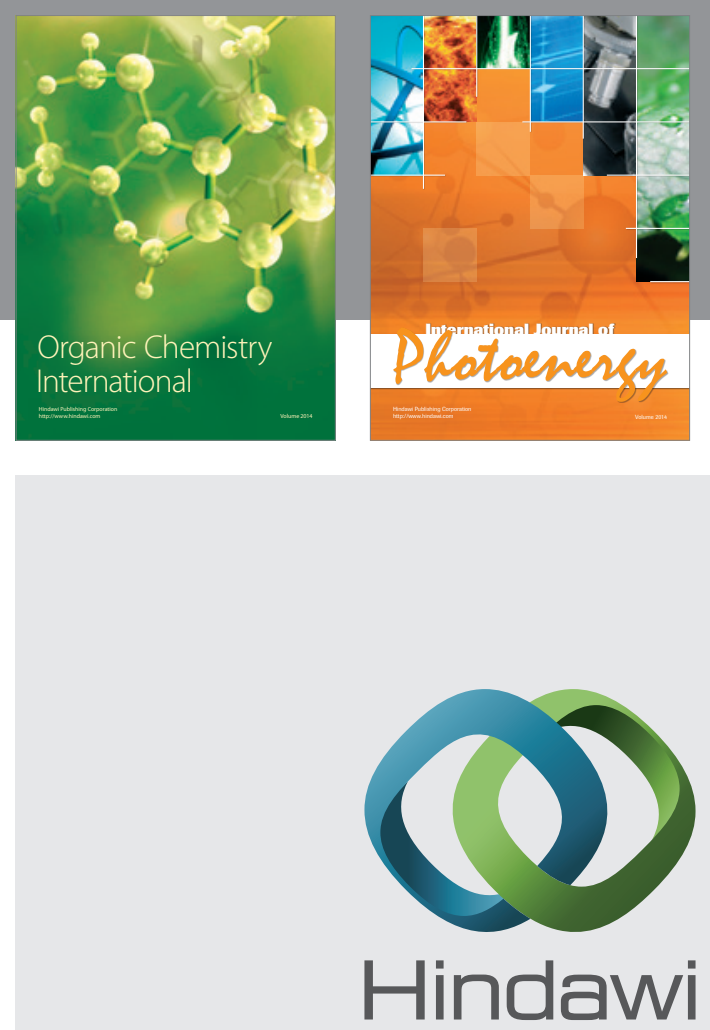

Submit your manuscripts at

http://www.hindawi.com
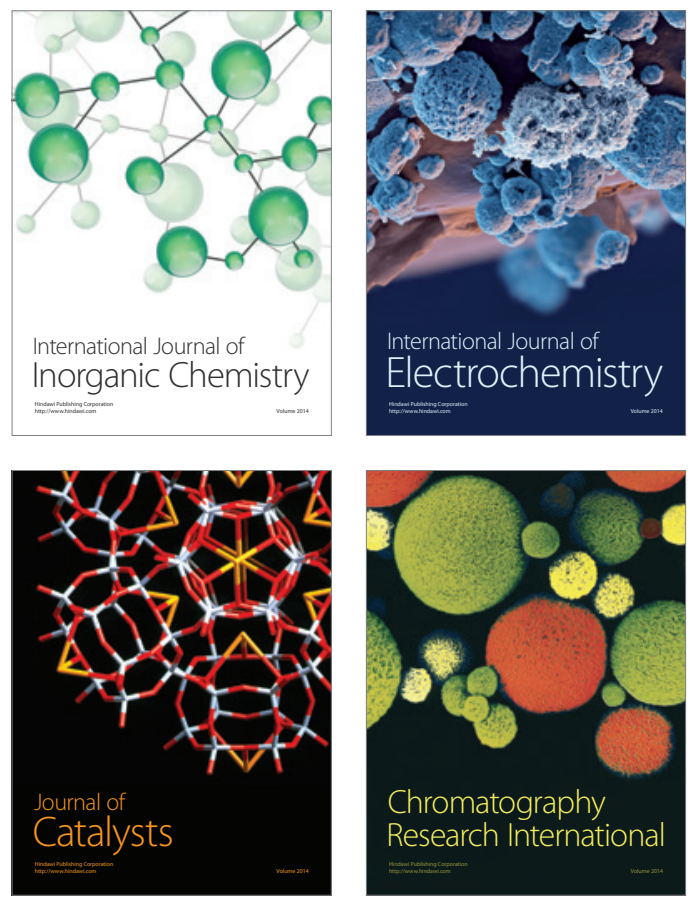
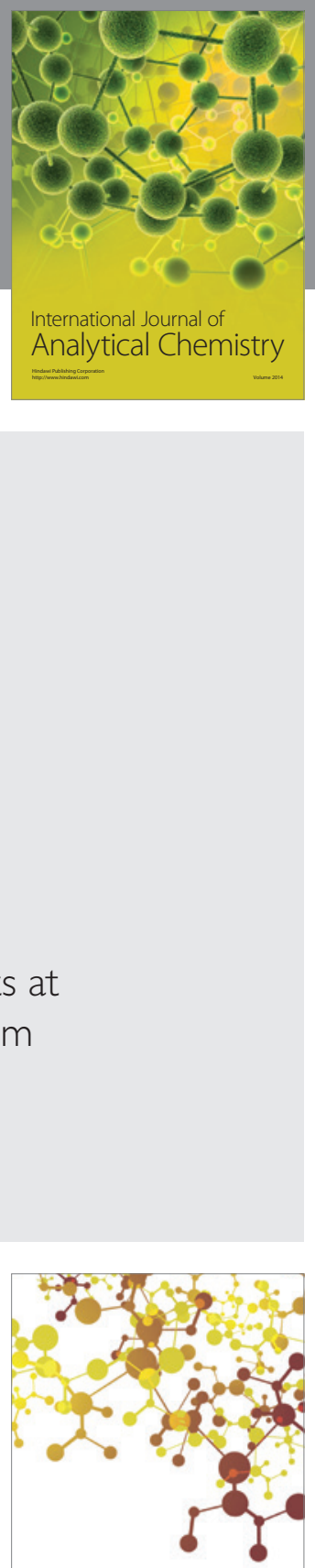

Journal of

Applied Chemistry
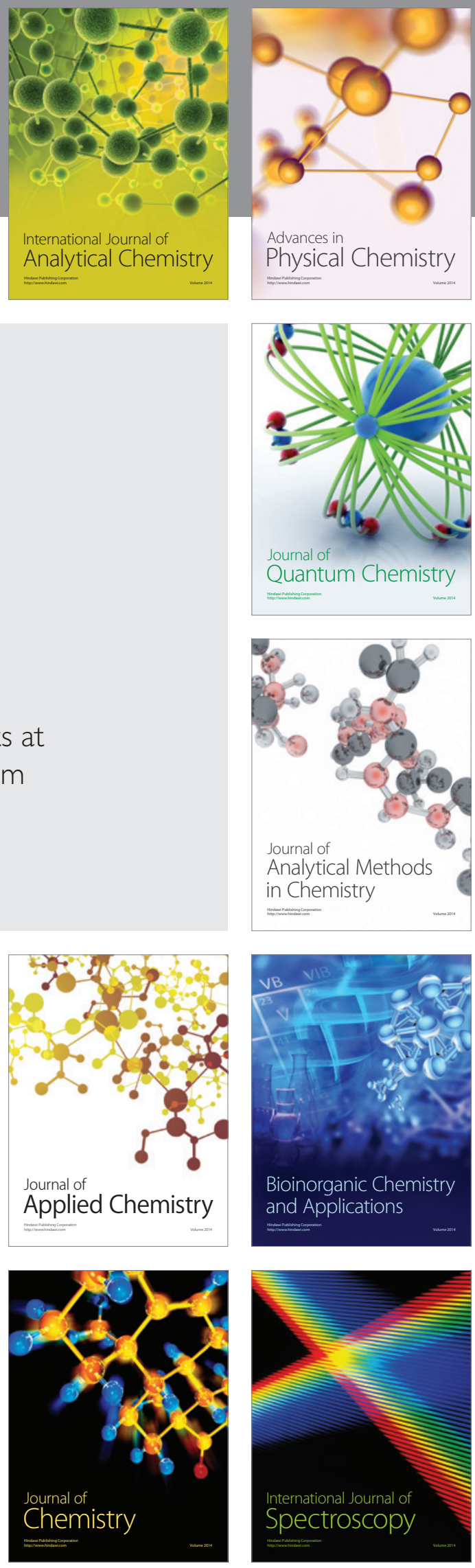